\title{
Antibacterial Activities of Actinomycete Isolates Collected from Soils of Rajshahi, Bangladesh
}

\author{
Md. Ajijur Rahman, ${ }^{1}$ Mohammad Zahidul Islam, ${ }^{2,3}$ and Md. Anwar Ul Islam ${ }^{1}$ \\ ${ }^{1}$ Department of Pharmacy, University of Rajshahi, Rajshahi 6205, Bangladesh \\ ${ }^{2}$ Department of Parasitology, Aichi Medical University, Aichi-ken 480-1195, Japan \\ ${ }^{3}$ Department of Biology, The Catholic University of America, Washington, DC 20064, USA
}

Correspondence should be addressed to Md. Anwar Ul Islam, profanwarulislam@yahoo.com

Received 23 April 2011; Accepted 26 May 2011

Academic Editor: Triantafyllos Roukas

Copyright (c) $2011 \mathrm{Md}$. Ajijur Rahman et al. This is an open access article distributed under the Creative Commons Attribution License, which permits unrestricted use, distribution, and reproduction in any medium, provided the original work is properly cited.

This study was performed to isolate actinomycete colonies having antibacterial activity from soil samples collected from different places around Rajshahi, Bangladesh. Thirty actinomycete colonies were isolated in pure culture from five soil samples using Starchcasein-nitrate-agar medium. The isolates were grouped in five color series based on their aerial mycelia color and screened for their antibacterial activity against a range of test bacteria. Sixteen isolates (53.3\%) were found to have moderate to high activity against four gram-positive and four gram-negative bacteria. Since many isolates showed inhibitory activity against indicator bacteria, it is suggestive that Bangladeshi soil could be an interesting source to explore for antibacterial secondary metabolites.

\section{Introduction}

Actinomycetes are gram-positive, free-living, saprophytic bacteria, widely distributed in soil, water, and colonizing plants. From the 22,500 biologically active compounds that have obtained form microbes, $45 \%$ are produced by actinomycetes, $38 \%$ by fungi, and $17 \%$ by unicellular bacteria [1]. The species belong to the genus Streptomyces constitute $50 \%$ of the total population of soil actinomycetes and are well known for producing a variety of bioactive secondary metabolites including antibiotics, immunomodulators, anticancer drugs, antiviral drugs, herbicides, and insecticides [24]. Streptomyces species are gram-positive, aerobic microorganisms with high DNA G+C contents and produce about half of all known antibiotics from microorganisms. In fact, Streptomyces species are the resource of $75 \%$ of commercially produced and medically useful antibiotics [5].

Although thousands of antibiotics have been isolated from Streptomyces, these represent only a small fraction of the repertoire of bioactive compounds produced $[4,6]$. Therefore, isolation of new Streptomyces from natural resources and characterization of their secondary metabolites is a valuable endeavor.
Bangladesh, a low-lying riverine country, has a tropical monsoon climate characterized by heavy seasonal rainfall, high temperatures, and high humidity. The alluvial soil of Bangladesh is highly fertile. A few studies have been done so far using Bangladeshi soils to screen for new actinomycetes for new bioactive compounds. Streptomyces bangladeshensis was the first report of the discovery of a new species of Streptomyces, from soil samples of Bangladesh producing bis-(2-ethylhexyl)-phthalate [7]. Actinomycin D was isolated from a new type strain of Streptomyces parvulus strain MARS-17, from soils collected from Rajshahi, Bangladesh [8].

This report describes the isolation of actinomycete strains producing antibacterial secondary metabolites from soil samples collected from different places around Rajshahi, Bangladesh.

\section{Materials and Methods}

2.1. Soil Samples. Soil samples were collected from the different places of Rajshahi District, Bangladesh (Table 1). Samples were collected from various depth of the earth 
TABLE 1: Collection site and depth of soil from where the isolates were collected using Starch-casein-nitrate-agar media.

\begin{tabular}{llcl}
\hline Date of collection & Collection site & $\begin{array}{c}\text { Number of actinomycetes in each gram } \\
\text { of soil (c.f.u/gm of dried weight soil) }\end{array}$ & \multicolumn{1}{c}{ Isolates } \\
\hline $11 / 02 / 2007$ & $\begin{array}{l}\text { Cultivated land for wheat production, } \\
\text { Rajshahi }\end{array}$ & $1.45 \times 10^{6}$ & MARS 1-10 \\
$12 / 02 / 07$ & Medicinal Plant Garden, Rajshahi & $1.27 \times 10^{6}$ & MARS 11-15 \\
$18 / 03 / 07$ & University & $1.11 \times 10^{6}$ & MARS 16-25 \\
$03 / 06 / 07$ & Bank of Pond, Rajshahi University & $1.20 \times 10^{6}$ & MARS 26-30 \\
\hline
\end{tabular}

TABLE 2: Color grouping of the isolates.

\begin{tabular}{|c|c|c|c|c|}
\hline Color series & Isolate & Color of aerial mycelia & $\begin{array}{c}\text { Color of substrate } \\
\text { mycelia }\end{array}$ & $\begin{array}{c}\text { Diffusible } \\
\text { pigment }\end{array}$ \\
\hline \multirow{10}{*}{ Gray series } & MARS-1 & Light gray & Light gray & $\mathrm{ND}^{*}$ \\
\hline & MARS-3 & Light brownish gray & Dark yellowish brown & ND \\
\hline & MARS-4 & Light brownish gray & Grayish red & ND \\
\hline & MARS-11 & Pinkish gray & Dark reddish brown & ND \\
\hline & MARS-17 & Light brownish gray & Grayish yellow & Yellow \\
\hline & MARS-20 & Brownish gray & Darky & ND \\
\hline & MARS-22 & Light gray & Grayish yellow & ND \\
\hline & MARS-25 & Light bluish gray & Tan & ND \\
\hline & MARS-27 & Medium bluish gray & Dusky red & Brown \\
\hline & MARS-30 & Very light gray & Grayish yellow & ND \\
\hline \multirow{7}{*}{ Brown series } & MARS-6 & Dark yellowish brown & Grayish yellow & $\mathrm{ND}$ \\
\hline & MARS-8 & Dark yellowish brown & Grayish yellow & ND \\
\hline & MARS-10 & Pale reddish brown & Dark yellowish orange & ND \\
\hline & MARS-12 & Pale brown & Grayish orange & $\mathrm{ND}$ \\
\hline & MARS-21 & Brownish black & Yellowish gray & ND \\
\hline & MARS-31 & Light brown & Grayish yellow & ND \\
\hline & MARS-32 & Dark reddish brown & Grayish orange & ND \\
\hline \multirow{3}{*}{ White series } & MARS-16 & White & Grayish orange & ND \\
\hline & MARS-23 & White & Grayish yellow & ND \\
\hline & MARS-28 & White & Moderate yellow & ND \\
\hline \multirow{7}{*}{ Orange series } & MARS-2 & $\begin{array}{c}\text { Moderate reddish } \\
\text { orange }\end{array}$ & Grayish orange & ND \\
\hline & MARS-5 & Pale yellowish orange & Grayish orange & ND \\
\hline & MARS-7 & Pale yellowish orange & Dark yellowish orange & ND \\
\hline & MARS-9 & Pale yellowish orange & Grayish orange & ND \\
\hline & MARS-15 & Grayish orange pink & Moderate yellow & $\mathrm{ND}$ \\
\hline & MARS-19 & Pale yellowish orange & Moderate yellow & ND \\
\hline & MARS-29 & Pale yellowish orange & Dark yellowish orange & ND \\
\hline \multirow{3}{*}{ Red series } & MARS-18 & Pale red & $\begin{array}{c}\text { Moderate yellowish } \\
\text { brown }\end{array}$ & ND \\
\hline & MARS-26 & Grayish red & Moderate yellow & ND \\
\hline & MARS-24 & Grayish red & Moderate yellow & ND \\
\hline
\end{tabular}

*ND: Not detectable.

surface, ranging from layers just beneath the upper surface to 1 meter depth. They were collected in the sterile small plastic tubes and properly labeled with the date of collection. Twenty soil samples were collected within a period of six months (July, 2007-December, 2007). The collected soil samples were dried in a hot air oven at $60-65^{\circ} \mathrm{C}$ for 3 hours and stored in $4^{\circ} \mathrm{C}$ until examined.

2.2. Isolation of Pure Culture of Actinomycetes. Thirty actinomycete strains were isolated and obtained as pure culture 


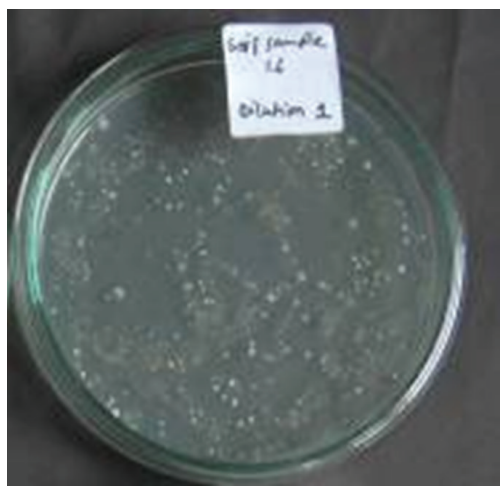

(a) Dilution $10^{-1}$

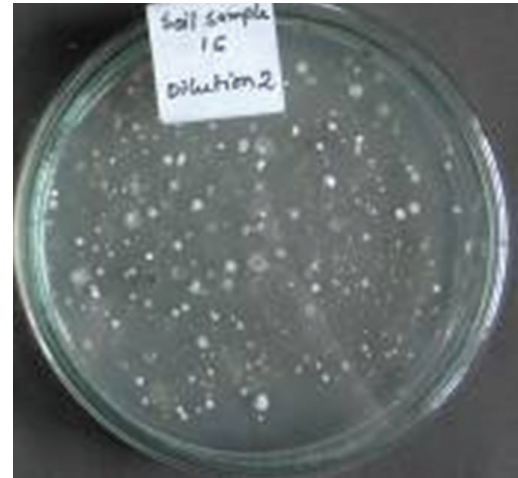

(b) Dilution $10^{-2}$

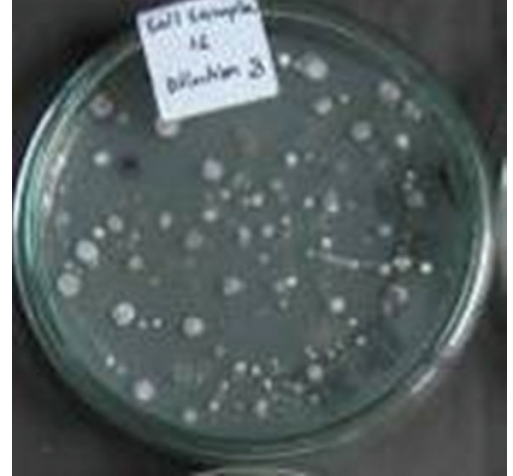

(c) Dilution $10^{-3}$

FIGURE 1: Colonies of actinomycetes appeared on the dilution plates using the soil samples collected from medicinal plant garden.

by using standard microbiological method. From each soil sample, $1 \mathrm{gm}$ of dried soil was suspended in $9 \mathrm{~mL}$ sterile water, and successive serial dilutions were made by transferring $1 \mathrm{~mL}$ of aliquots to $2 \mathrm{nd}$ test tube containing $9 \mathrm{~mL}$ of sterile water, and in this way dilutions up to $10^{-4}$ were prepared. Each time the contents were vortexed to form uniform suspension. An aliquot of $0.1 \mathrm{~mL}$ of each dilution was taken and spread evenly over the surface of starch-caseinnitrate-agar medium supplemented with cycloheximide $(100 \mu \mathrm{g} / \mathrm{mL})$ on $16 \mathrm{~cm}$ petridishes. Plates were incubated at $32^{\circ} \mathrm{C}$ and monitored for 7 days. The colonies were carefully counted by visual observation and c.f.u per gram of soil was determined. Plates those gave 100-150 colonies were chosen for further isolation in pure culture. Suitable colonies those showed Streptomyces like appearance under light microscope were recultivated several times for purity. The purified actinomycetes were preserved on yeast-extract-glucose-agar slants at $4^{\circ} \mathrm{C}$ for two months and at $-20^{\circ} \mathrm{C}$ in the presence of glycerol $(15 \% \mathrm{v} / \mathrm{v})$ for longer periods.

2.3. Color Grouping of the Isolates. The color of the aerial mycelia and pigment production by the isolates were determined on yeast-extract-glucose-agar plates after 7 days of incubation at $32^{\circ} \mathrm{C}$. The color of the substrate mycelia and those of the soluble pigment were determined according to the National Bureau of Standards Color Chart [9].

2.4. Screening of Antimicrobial Activities of Pure Isolates. Preliminary screening for antibiotic activity of the isolates was done by using streak-plating technique on yeast-extract-glucose-agar medium. Each pure isolates were streaked individually on different agar plates in a single line. The plates were then incubated at $32^{\circ} \mathrm{C}$ for 5 days to allow the isolates to secrete antibiotics into the medium. After the incubation period, the properly diluted test organisms were crossstreaked along the line of fully grown isolates. Each streaking was started near the edge of the plates and streaked toward the Streptomyces growth line. The plates were then incubated for $12 \mathrm{hrs}$ at $37^{\circ} \mathrm{C}$, and the zone of inhibition was measured using a millimeter scale [10].
2.5. Test Organisms. Eight test organisms were used to test the antibiotic activity of the isolates. Four of them were gram-positive and four were gram-negative bacteria. Grampositive species were Staphylococcus aureus ATCC-259233, Streptococcus agalactiae, Bacillus cereus, and Bacillus megaterium QL-40. Gram-negative strains were Escherichia coli FPFC-1407, Shigella flexneri AL-30372, Shigella dysenteriae AL-35587, and Shigella sonnei. They were maintained in nutrient agar slants at $4^{\circ} \mathrm{C}$.

\section{Results and Discussion}

This study was performed with an aim of isolating actinomycete strains with antimicrobial activities using the selective isolation media. Thirty different actinomycete strains were isolated from 5 soil samples collected from different locations of Rajshahi (Table 1) in the year of 2007. All of these strains were collected by using Starch-casein-nitrate-agar media supplemented with cycloheximide $(100 \mu \mathrm{g} / \mathrm{mL})$ to inhibit fungal growth. This media is very specific for the isolation of actinomycetes, as only organisms (mostly actinomycetes) those are capable of degrading the polymers in the media are able to grow [11]. The colony forming units (c.f.u) were determined by counting the colonies on the dilution plates (Figure 1). Maximum number of colonies $(1.45 \times$ 106 c.f.u/gm of soil) were obtained in the soil collected from the cultivated land. This land is used for wheat cultivation. This cultivated land was near to a small lake and was very rich with natural composts which may be the reason for highest count. The result of colony counts is shown in Table 1 .

All purified isolates grew on yeast-extract-glucose-agar media showing morphology of typical Streptomyces; the colonies were slow growing, aerobic, glabrous or chalky, folded, and with aerial and substrate mycelia of different colors [12]. In addition, all colonies possessed an earthy odor. All of the strains were acid fast negative and gram positive and fitted to the description of genus Streptomyces in Bergey's Manual of Systemic Bacteriology. The isolates were categorized into five color series according to their color of the mature sporulated substrate mycelium (Figure 2, Table 2). The gray series isolates were more predominant 


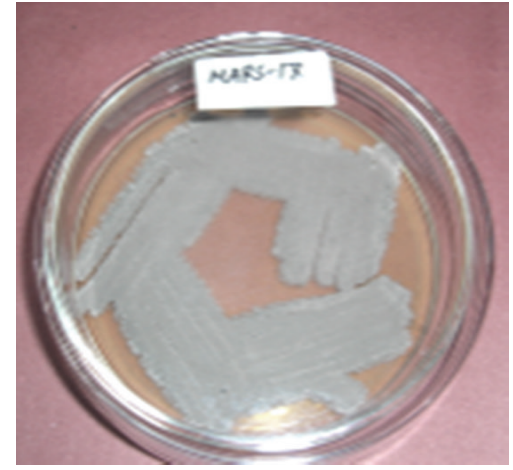

(a) MARS-17

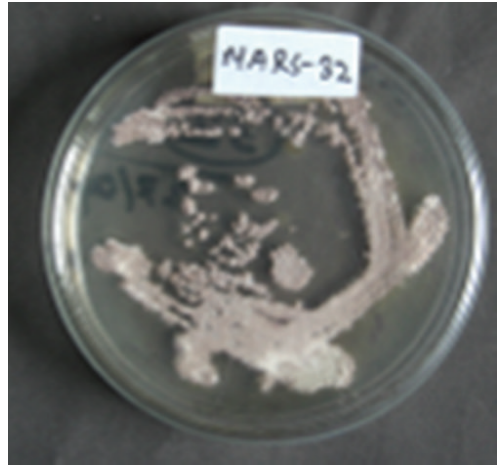

(b) MARS-32

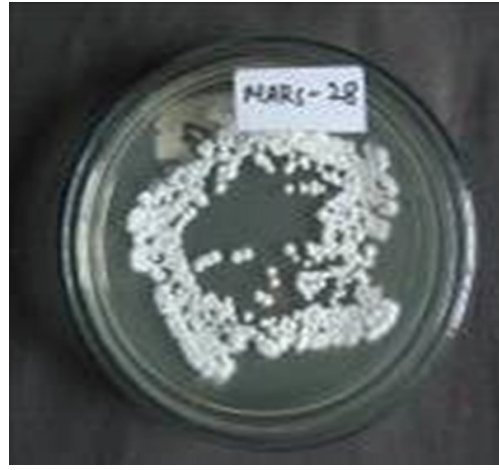

(c) MARS-28

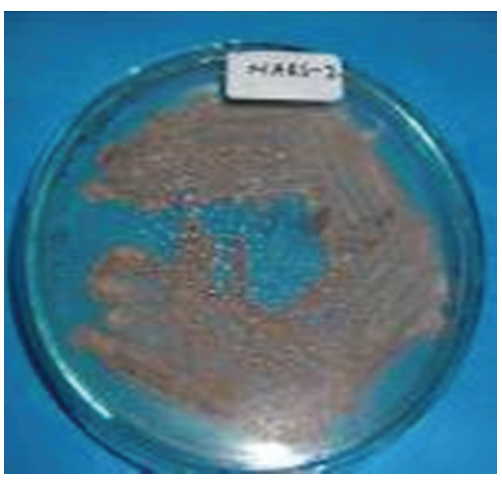

(d) MARS-2

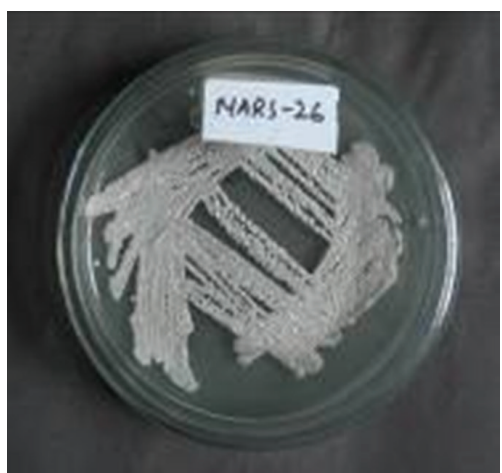

(e) MARS-26

FIGURE 2: Representative isolates of different color series (a) MARS-17, gray series, (b) MARS-32, brown series, (c) MARS-28, white series, (d)MARS-2, orange series, (e) MARS-26, red series. The isolates were grown on yeast-extract-glucose-agar plates for 7 days at $32^{\circ} \mathrm{C}$.

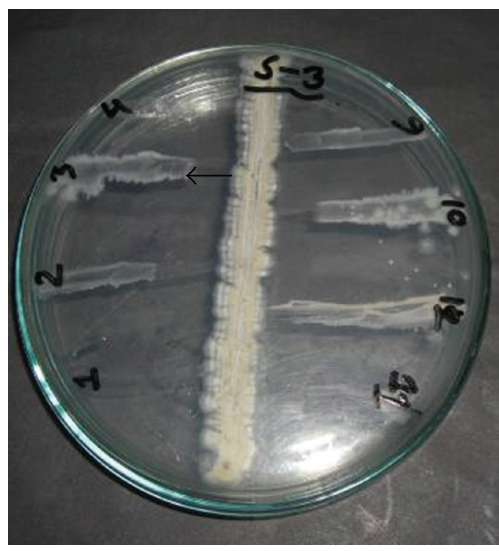

(a)

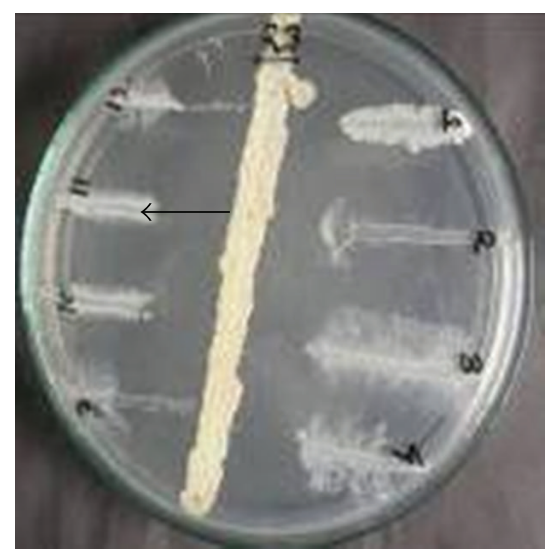

(b)

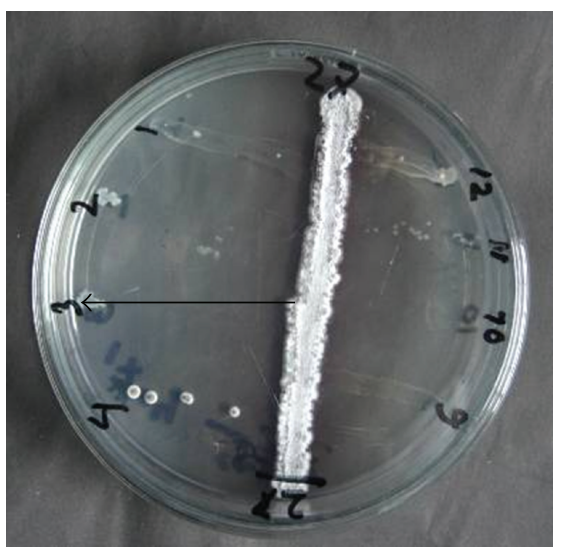

(c)

Figure 3: Streak-plating technique to screen the antibacterial activity of isolated Streptomyces. The vertical line is the Streptomyces strains to be tested and. $(\longrightarrow)$ indicates the distance in millimeter $(\mathrm{mm})$ inhibited by the isolates. (a) MARS-3, a low active strain, (b) MARS-23, a moderately active strain, (c) MARS-27, a highly active strain. The perpendicular lines marked with numerical digits are the test organismStaphylococcus aureus ATCC-259233 (1), Streptococcus agalactiae (2), Bacillus cereus (3), Bacillus megaterium QL-40 (4), Escherichia coli FPFC-1407 (9), Shigella flexneri AL-30372 (10), Shigella dysenteriae AL-35587 (11), and Shigella sonnei (12).

(33.3\% of the total isolates). Out of 30 isolates, two isolates produce soluble pigments in the media (Table 2).

All the isolated actinomycete strains were screened for their antibacterial activity on Yeast-extract-glucose-agar medium using streak-plating technique (Figure 3). A broad spectrum of antibacterial activity was observed in 53.3\% (16 out of 30) of the total pure isolates. Percentages of active isolates in between the series were different. About $60.0 \%$ of the gray series, $28.0 \%$ of brown series, $100.0 \%$ of white series, $42.0 \%$ orange series, and $66.0 \%$ of red series isolates 
TABLE 3: Antibacterial activity of the isolates against a wide range of test bacteria.

\begin{tabular}{|c|c|c|c|c|c|c|c|c|}
\hline \multirow{3}{*}{$\begin{array}{l}\text { Bacteria } \\
\text { Isolates }\end{array}$} & \multicolumn{8}{|c|}{ Zone of inhibition } \\
\hline & \multicolumn{4}{|c|}{ Gram-positive bacteria } & \multicolumn{4}{|c|}{ Gram-negative bacteria } \\
\hline & S. aureus & S. agalactiae & B. cereus & B. megaterium & E. coli & S. flexneri & S. dysenteriae & S. sonnei \\
\hline MARS-3 & 24 & 08 & 08 & 08 & 0 & 08 & 0 & 10 \\
\hline MARS-4 & 24 & 23 & 06 & 24 & 0 & 31 & 21 & 34 \\
\hline MARS-17 & 43 & 42 & 45 & 45 & 40 & 44 & 43 & 25 \\
\hline MARS-20 & 10 & 10 & 10 & 10 & 11 & 10 & 10 & 10 \\
\hline MARS-22 & 15 & 14 & 17 & 20 & 25 & 19 & 21 & 20 \\
\hline MARS-27 & 0 & 41 & 38 & 36 & 0 & 30 & 26 & 0 \\
\hline MARS-21 & 0 & 5 & 4 & 5 & 5 & 4 & 3 & 0 \\
\hline MARS-31 & 20 & 16 & 15 & 32 & 15 & 15 & 16 & 12 \\
\hline MARS-16 & 18 & 20 & 16 & 20 & 0 & 23 & 17 & 19 \\
\hline MARS-23 & 15 & 14 & 17 & 20 & 25 & 19 & 21 & 20 \\
\hline MARS-28 & 21 & 25 & 25 & 26 & 0 & 24 & 23 & 0 \\
\hline MARS-2 & 0 & 24 & 24 & 26 & 23 & 22 & 24 & 22 \\
\hline MARS-5 & 15 & 10 & 10 & 16 & 06 & 13 & 11 & 08 \\
\hline MARS-19 & 20 & 20 & 18 & 18 & 15 & 10 & 10 & 10 \\
\hline MARS-18 & 22 & 21 & 18 & 20 & 0 & 21 & 24 & 24 \\
\hline MARS-26 & 21 & 21 & 20 & 24 & 22 & 05 & 05 & 24 \\
\hline
\end{tabular}

were active against the test bacteria (Figures 4 and 5, Table 3).

The active isolates exhibited different inhibitory patterns against the test organisms. S. aureus and $S$. sonnei were inhibited by 13 isolates (81.25\%), S. agalactiae, B. cereus, B. megaterium, and $S$. flexneri were inhibited by all 16 isolates (100.0\%), E. coli by 10 isolates (62.5\%), and S. dysenteriae by 15 isolates $(93.75 \%)$. MARS-3 could not inhibit E. coli, and S. dysenteriae (gram-negative bacteria) but exhibited strong activity against $S$. aureus. MARS- 4 could not suppress the growth of E. coli but strongly inhibited $S$. dysenteriae and $S$. sonnei. MARS-27 were inactive against S. aureus, S. sonnei, and $E$. coli but were strongly active against other test bacteria. MARS-21 did not exhibit any activity against $S$. aureus, and $S$. sonnei but showed very weak activity against other test organisms. MARS-16 and MARS-18 were moderate active against all but E. coli. MARS-28 could not inhibit E. coli and $S$. dysenteriae but was moderately active against the others. MARS-5, MARS-17, MARS-19, MARS-20, MARS22, MARS-23, MARS-26, and MARS-31 inhibited all test organisms. Among them, the isolate MARS-17 and MARS27 showed very strong broad-spectrum antibacterial activity (Figures 4 and 5). These two highly active isolates were under gray series.

In a study, from the soil samples of Karanjal regions of Sundarbans of Bangladesh, about 55 actinomycetes of different genera were isolated and screened for antibacterial activity [13]. In their screening work, they found that 20 isolates $(36.36 \%)$ were active against the test organisms. In another study, 356 Streptomyces isolates were obtained from soils in the Aegean and East Black Sea regions of Turkey, and $36 \%$ of the isolates were found to be active against tested microorganisms [14]. In a recent study performed in 2010 by Dehand et al., [15], the antibacterial activity of Streptomyces isolates from soil samples of West of Iran was investigated.

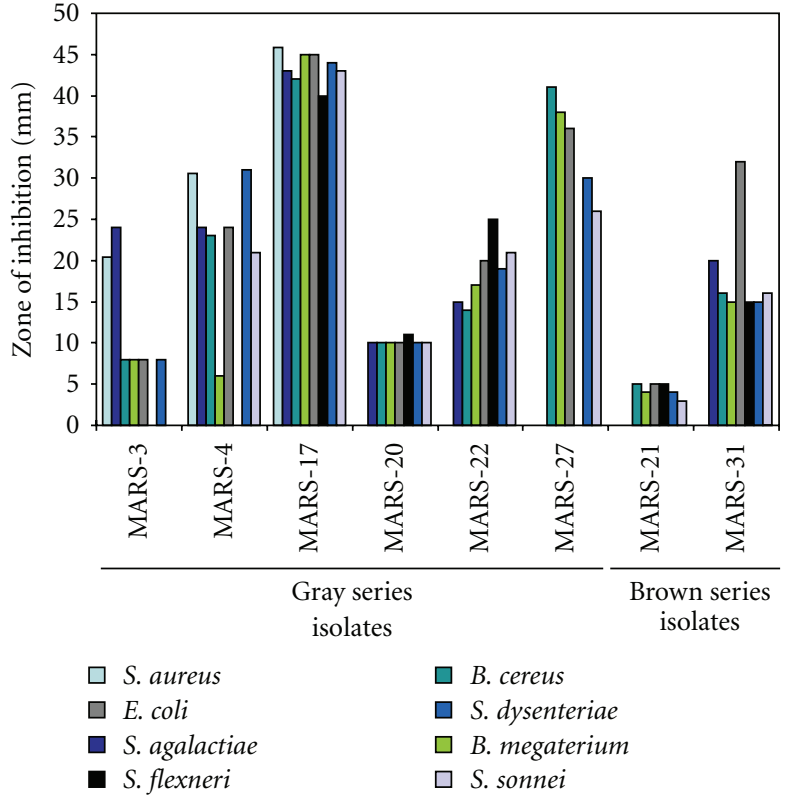

FIGURE 4: Antibacterial activities of gray and brown series isolates. Only the antibacterial activities of the active isolates have been shown. The zone of inhibition was measured using a millimeter scale from the line of streaking as shown in Figure 3.

Out of 150 actinomycetes, only 20 isolates (13.30\%) showed activity against the test bacteria.

Comparing the above mentioned results with this study, we can conclude that the soil samples of Rajshahi are rich source of actinomycetes which produce metabolites inhibitory to bacterial pathogens. We found that $53.3 \%$ of the isolated colonies were active against the test bacteria. MARS17 and MARS-27 were very active and showed very large zone 


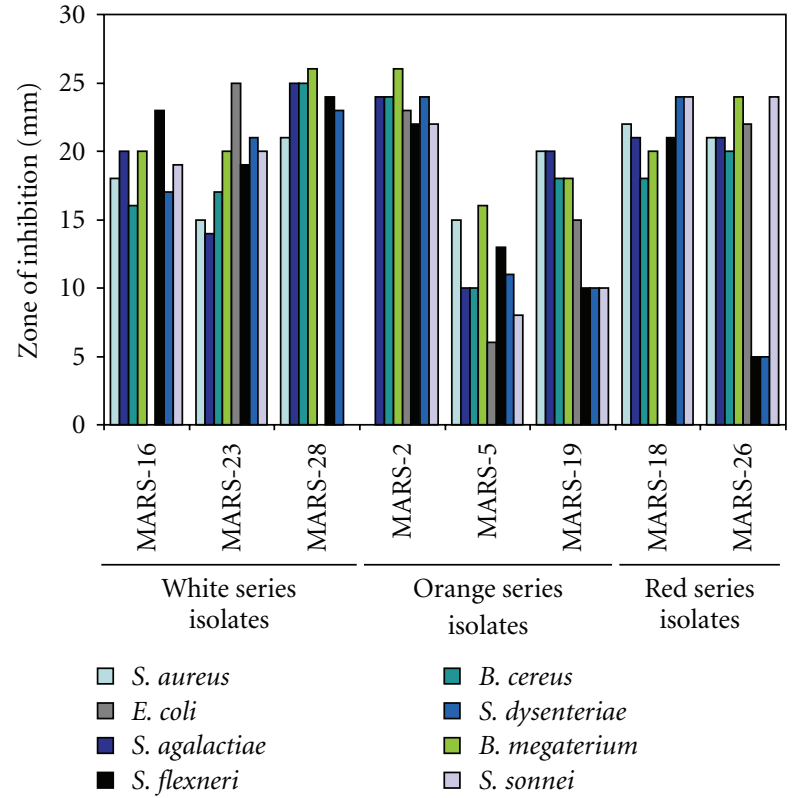

Figure 5: Antibacterial activities of white, orange and red series isolates. Only the antibacterial activities of the active isolates have been shown. The zone of inhibition was measured using a millimeter scale from the line of streaking as shown in Figure 3.

of inhibition. Future studies will be done to identify the active isolates up to the species level. The type of antimicrobial agents produced by these isolates will be investigated as well.

\section{Acknowledgments}

This work was partly supported by the National Science and Information and Communication Technology (NSICT) fellowship funded by The Ministry of Science and Communication Technology, Govt. of Bangladesh and mostly by the support of Pharmacy Department, Rajshahi University. These contributions are gratefully acknowledged.

\section{References}

[1] J. Berdy, "Bioactive microbial metabolites: a personal view," Journal of Antibiotics, vol. 58, no. 1, pp. 1-26, 2005.

[2] L. C. Vining, "Functions of secondary metabolites," Annual Review of Microbiology, vol. 44, pp. 395-427, 1990.

[3] J. J. Sanglier, H. Haag, T. A. Huck, and T. Fehr, "Novel bioactive compounds from actinomycetes: a short review (1988-1992)," Research in Microbiology, vol. 144, no. 8, pp. 633-642, 1993.

[4] J. Berdy, "Are Actinomycetes exhausted as a source of secondary metabolites?" in Proceedings of the 9th Symposium Actinomycetes, pp. 13-34, 1995.

[5] S. Miyadoh, "Research on antibiotic screening in Japan over the last decade: a producing microorganisms approach," Actinomycetologica, vol. 9, pp. 100-106, 1993.

[6] M. G. Watve, R. Tickoo, M. M. Jog, and B. D. Bhole, "How many antibiotics are produced by the genus Streptomyces?" Archives of Microbiology, vol. 176, no. 5, pp. 386-390, 2001.
[7] M. A. A. Al-Bari, M. S. A. Bhuiyan, M. E. Flores, P. Petrosyan, M. Garcia-Varela, and M. A. Islam, "Streptomyces bangladeshensis sp. nov., isolated from soil, which produces bis-(2ethylhexyl)phthalate," International Journal of Systematic and Evolutionary Microbiology, vol. 55, no. 5, pp. 1973-1977, 2005.

[8] M. A. Rahman, M. Z. Islam, P. Khondkar, and M. A. Islam, "Characterization and antimicrobial activities of a polypeptide antibiotic isolated from a new strain of Streptomyces parvulus," Bangladesh Pharmaceutical Journal, vol. 13, no. 1, pp. 14-16, 2010.

[9] H. Zhao, R. L. Parry, D. I. Ellis, G. W. Griffith, and R. Goodacre, "The rapid differentiation of Streptomyces isolates using fourier transform infrared spectroscopy," Vibrational Spectroscopy, vol. 40, no. 2, pp. 213-218, 2006.

[10] T. Shomura, S. M. Omoto, K. Ohba, and H. Ogino, "SF-1961, a new antibiotic related to bleomycin," Journal of Antibiotics, vol. 33, no. 11, pp. 1243-1248, 1980.

[11] A. L. Demain and J. E. Davies, Manual of Industrial Microbiology and Biotechnology, chapter 1, American Society for Microbiology, Washington, DC, USA, 2nd edition, 1999.

[12] A. S. Anderson and E. M. H. Wellington, "The taxonomy of Streptomyces and related genera," International Journal of Systematic and Evolutionary Microbiology, vol. 51, no. 3, pp. 797-814, 2001.

[13] M. Arifuzzaman, M. R. Khatun, and H. Rahman, "Isolation and screening of actinomycetes from Sundarbans soil for antibacterial activity," African Journal of Biotechnology, vol. 9, no. 29, pp. 4615-4619, 2010.

[14] A. A. Denizci, Ege ve DoÛu Karadeniz b.lgesi topraklarinden izole edilen aktinomisetlerden antibakteriyal antibiyotiklerin aranmasÝ ve retimi. zerine bir araßtÝrma, Doctoral thesis, Ege Üniversitesi Fen Bilimleri Enstitüsü, 1996.

[15] A. Dehnad, L. Parsa, R. Bakhshi, S. A. Soofiani, and A. Mokhtarzadeh, "Investigation antibacterial activity of Streptomycetes isolates from soil samples, West of Iran," African Journal of Microbiology Research, vol. 4, no. 14, pp. 1542-1549, 2010. 

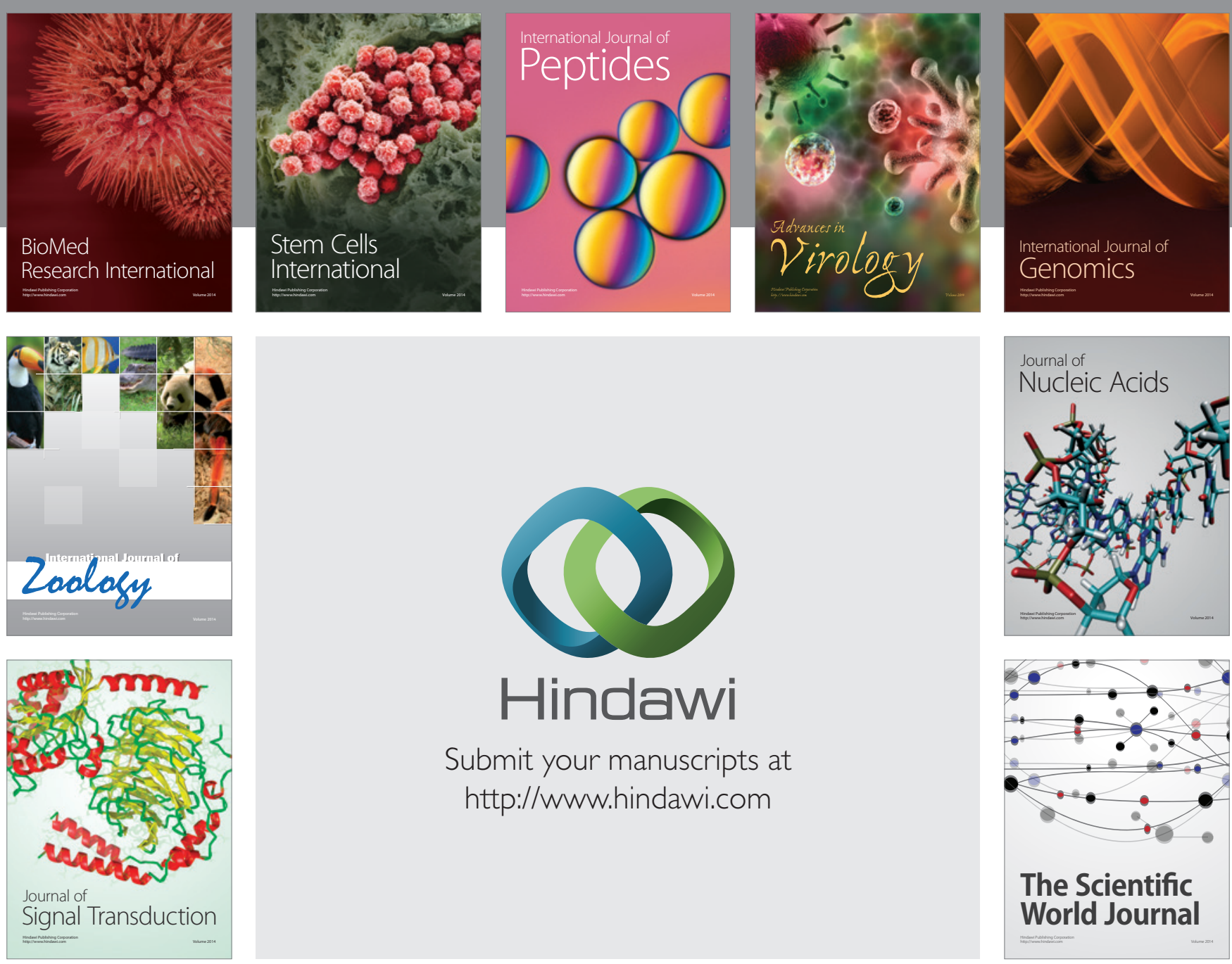

Submit your manuscripts at

http://www.hindawi.com
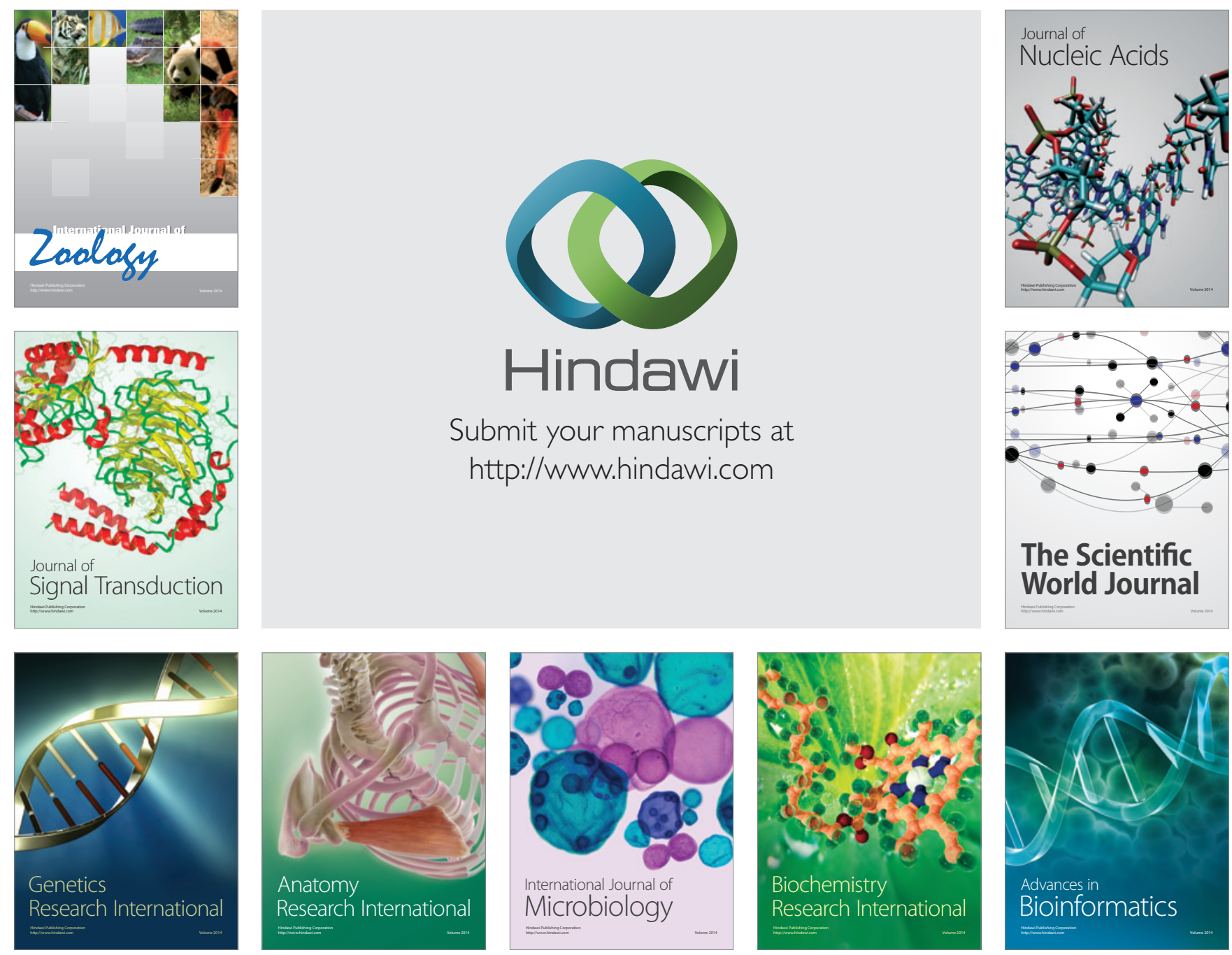

The Scientific World Journal
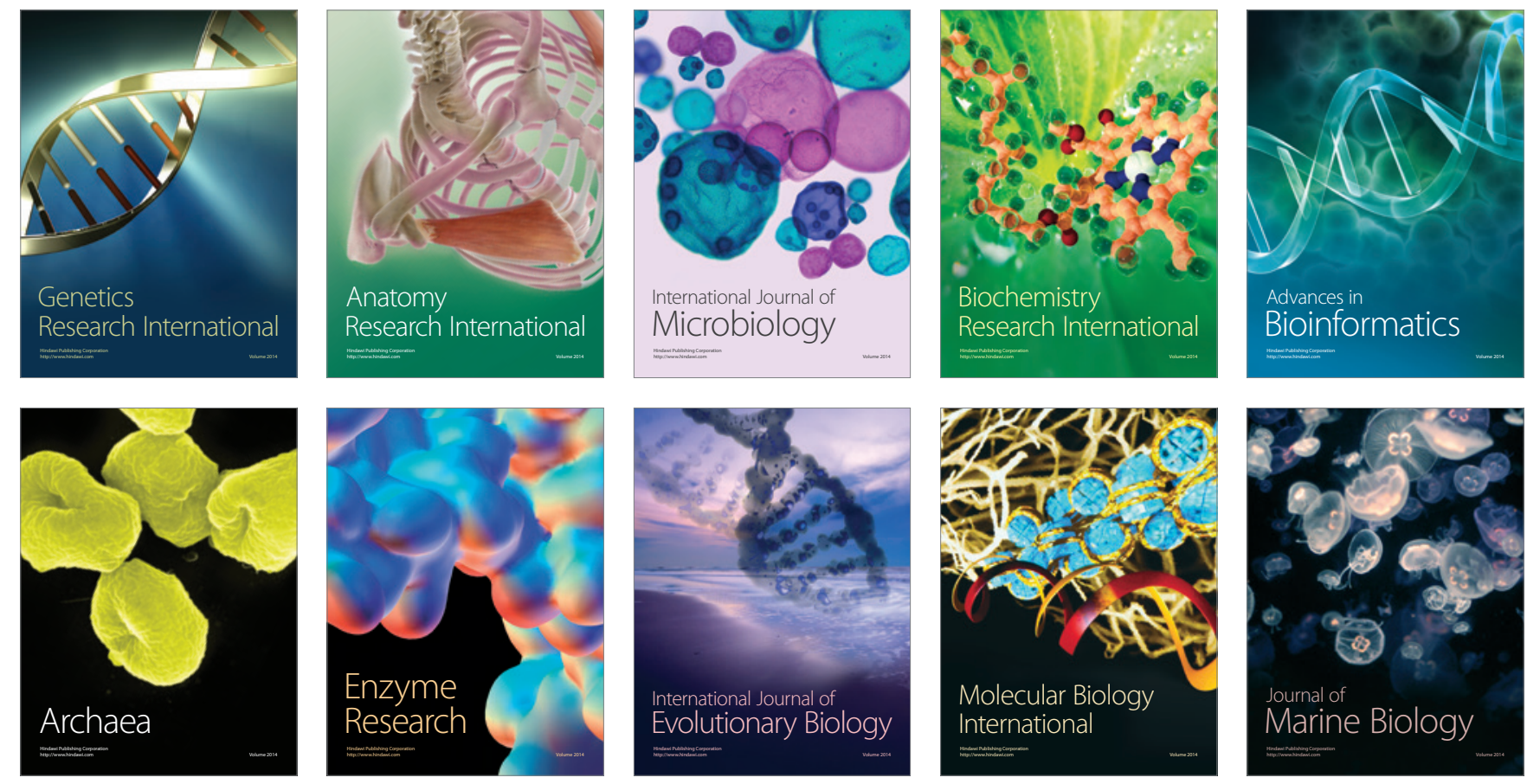